TITLE:

\title{
The effect of cultivating diagram use on the quality of EFL students' written explanations
}

$\operatorname{AUTHOR}(S):$

Manalo, Emmanuel; Tsuda, Ayano; Dryer, Rachel

\section{CITATION:}

Manalo, Emmanuel ... [et al]. The effect of cultivating diagram use on the quality of EFL students' written explanations. Thinking Skills and Creativity 2019, 33: 100588.

ISSUE DATE:

2019-09

URL:

http://hdl.handle.net/2433/243856

\section{RIGHT:}

(c) 2019. This manuscript version is made available under the CC-BY-NC-ND 4.0 license

http://creativecommons.org/licenses/by-nc-nd/4.0/; The full-text file will be made open to the public on 1 September 2021 in accordance with publisher's 'Terms and Conditions for Self-Archiving'; この論文は出版社版でありません。引用 の際には出版社版をご確認ご利用ください。; This is not the published version. Please cite only the published version. 


\section{Accepted Manuscript}

Title: The Effect of Cultivating Diagram Use on the Quality of EFL Students' Written Explanations

Authors: Emmanuel Manalo, Ayano Tsuda, Rachel Dryer

PII: $\quad$ S1871-1871(18)30283-9

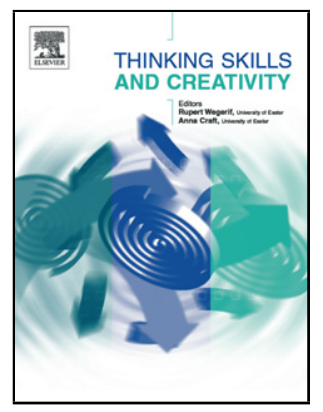

DOI:

Article Number: 100588

Reference: $\quad$ TSC 100588

To appear in: $\quad$ Thinking Skills and Creativity

Received date: $\quad 24$ August 2018

Revised date: $\quad 6$ June 2019

Accepted date: $\quad 24$ July 2019

Please cite this article as: Manalo E, Tsuda A, Dryer R, The Effect of Cultivating Diagram Use on the Quality of EFL Students' Written Explanations, Thinking Skills and Creativity (2019), https://doi.org/10.1016/j.tsc.2019.100588

This is a PDF file of an unedited manuscript that has been accepted for publication. As a service to our customers we are providing this early version of the manuscript. The manuscript will undergo copyediting, typesetting, and review of the resulting proof before it is published in its final form. Please note that during the production process errors may be discovered which could affect the content, and all legal disclaimers that apply to the journal pertain. 
The Effect of Cultivating Diagram Use on the Quality of EFL Students' Written Explanations

Running head: USING DIAGRAMS IN WRITING EXPLANATIONS

Emmanuel Manalo

Graduate School of Education, Kyoto University, Kyoto, Japan

Ayano Tsuda

Graduate School of Education, Kyoto University, Kyoto, Japan

Rachel Dryer

Australian Catholic University, Sydney, Australia

Address for correspondence:

Emmanuel Manalo, Graduate School of Education, Kyoto University, Yoshida-Honmachi, Sakyo-ku, Kyoto 606-8501, Japan.

Telephone: +81-90-6672-2075

Email: manalo.emmanuel.3z@kyoto-u.ac.jp

Date of revision submission: June 7, 2019

\section{Highlights}

- English as a foreign language students were taught diagram use in explanation writing

- The quantity and types of diagrams they included in their explanations increased

- Diagram use resulted in more concise and simpler explanations

- Despite the conciseness and simplicity, important points were conveyed effectively

- Diagram use provides more creative and efficacious options in communicating

\section{ABSTRACT}


This study investigated how an intervention that promoted the use of diagrams might affect quality features of written explanations produced by EFL (English as a foreign language) students in an undergraduate education studies course taught entirely in English. At the beginning (Preinstruction) and end (Post-instruction) of the semester, the 19 student participants were administered a task that required reading a passage and writing an explanation of it. During the semester they had a weekly homework task of writing an explanation of what they had learned in the course. They were additionally provided workshop instruction and practice in using diagrams. Analyses of the students' homework and Pre- and Post-instruction explanations revealed increases in quantity and types of diagrams the students included in explanations they produced. Analysis of Post-instruction explanations also showed that number of diagrams included in the explanations negatively correlated with both word- and verb-counts. However, despite the reduction in use of words, the number of key points the students were able to include in their explanations did not decrease. These findings suggest diagram inclusion may enable students to construct more concise and simpler explanations without having to sacrifice inclusion of important points. Especially for foreign language students who may not be as proficient in the use of the language, the cultivation of competencies in appropriate use of diagrams may be beneficial as it could provide a means to more creatively and efficaciously communicating what they know.

Keywords: Self-generated Diagrams; Written Communication; Creativity in Explaining; English as a Foreign Language Students; Diagram Use Instruction 
The Effect of Cultivating Diagram Use on the Quality of EFL Students' Written Explanations

\section{$1 \quad$ INTRODUCTION}

\subsection{Benefits of and Problems (and Possible Solutions) in Student Diagram Use}

The research literature concerning diagram use in learning, problem solving, and communication mostly indicates that such use is beneficial and efficacious (e.g., Ainsworth, Prain, \& Tytler, 2011; Cromley, Snyder-Hogan, \& Luciw-Dubas, 2010; Hembree, 1992; Larkin \& Simon, 1987; Mayer, 1989, 2005; Uesaka \& Manalo, 2017). However, the majority of studies in this area have focused on the effects of providing diagrams on learning performance and outcomes, rather than on cultivating competencies in constructing diagrams or examining the mechanisms involved in such construction. Thus, in typical experiments, participants would be provided with information to learn or problems to solve, some of which would contain diagrams while others would not (typically, only text information), and resulting student learning performance and outcomes would be evaluated (e.g., Bui \& McDaniel, 2015; Mayer, 1989; Chu, Rittle-Johnson, \& Fyfe, 2017; Sithole, Chandler, Abeysekera, \& Paas, 2017). While such studies serve the important purpose of extending knowledge and pertinent educational practices (e.g., effective incorporation of diagrams in textbooks and other instructional materials), they do not address what is widely considered a crucial objective of education in 21st Century learning environments, and that is the cultivation of student competencies in creating and using multiple and varied representations of information, concepts, and tasks. Such competencies are considered essential as they directly contribute to enabling deeper understanding and transfer of knowledge and skills (e.g., National Research Council, 2012).

The smaller proportion of research studies that have examined self-constructed diagrams in students have mostly reported beneficial consequences of such construction and use in learning contexts (e.g., Chen, Manalo, \& She, 2019; Leopold, \& Leutner, 2012; Uesaka, Manalo, \& Ichikawa, 2007). However, problems have also been identified, and those include a general lack of spontaneity among students in using diagrams to execute various learning tasks (e.g., DufourJanvier, Bednarz, \& Belanger, 1987; Manalo, Uesaka, Kriz, Kato, \& Fukaya, 2013; Uesaka et al., 2007) and, when they do use diagrams, students do not always benefit from such use (e.g., De Bock, Verschaffel, Janssens, Van Dooren, \& Claes, 2003; Hegarty, \& Kozhevnikov, 1999).

The second of these problems can probably be attributed to students' lack of adequate knowledge and skills in diagram construction and use. While teachers often use diagrams in teaching problem solving and other subject content in classrooms, they rarely provide explicit 
training to students on the construction and use of diagrams (Uesaka \& Manalo, 2017). It is therefore not surprising that in a study by Booth and Koedinger (2012), the results revealed that only older and higher ability middle school students benefited from the inclusion of diagrams in story problems - the younger and lower ability students did not. Such findings indicate that the development of student competencies in diagram comprehension and use is not something that can be taken for granted. In fact, when appropriate training in diagram construction and use is provided, learning performance benefits do tend to follow (e.g., Stull \& Hegarty, 2016; Pedalkar \& Hegarty, 2015). In the Padalkar and Hegarty study, for example, undergraduate students taking organic chemistry were provided an intervention during which they received instruction on diagram translation with the use of models. Even though the intervention did not take a lot of time to implement (less than 20 minutes), their results revealed that in posttests that assessed the students' representational competence in organic chemistry, those who received the intervention significantly outperformed those who did not.

Likewise, where the first-mentioned problem of lack of spontaneity in diagram use is concerned, the provision of appropriate skills training to cultivate both declarative and procedural knowledge in diagram use (i.e., to know what diagrams to use and how to create such diagrams) has been indicated as one of the key components of a viable solution. Uesaka and Manalo (2017) explained that at least two instructional components are required to effectively promote spontaneity in diagram use, and one of those is the provision of such skills training. The other requirement they proposed is raising student awareness and encouraging their perceptions about the efficacy that diagram use brings to tasks being undertaken. In other words, students need to appreciate the relevance and personal value of using diagrams when they are undertaking many learning or learning-related tasks such as problem solving, communicating information to others, comprehending complex concepts, integrating information from multiple sources, generating ideas, and so on. When either or both of these components are missing, students are unlikely to use diagrams of their own volition.

The findings from research specifically focusing on the promotion of diagram use spontaneity among students support the idea of the two components that Uesaka and Manalo (2017) proposed. In the area of math word problem solving, for example, implementation of interventions that include those components has resulted in increased spontaneity in diagram construction and use (e.g., Uesaka \& Manalo, 2007; Uesaka, Manalo, \& Ichikawa, 2010). More recently, similar results have been reported in the area of written communication: Manalo and Uesaka (2016) showed that providing an intervention that comprised a hint about the usefulness 
of diagrams, instruction about appropriate use of diagrams, and practice in constructing diagrams improved student spontaneity in diagram use when writing explanations.

It appears therefore that, although research has identified various problems concerning the cultivation of student competencies in creating and using diagrams, there are viable solutions to those problems. Thus, although a lot more research needs to be undertaken on the cultivation of such competencies, one of the objectives of 21st Century education mentioned earlier - that of equipping students with the necessary knowledge and skills in the use of multiple representations (National Research Council, 2012) - may be possible to achieve. However, as is typical in research, answers and solutions generate more questions and/or problems, and here one important question that arises is: What actually happens when students are able to use diagrams more? For instance, how does that affect the work they produce? In the present research, this question was explored in a natural setting (i.e., an actual classroom) where student-generated written explanations were concerned.

\subsection{Diagrams in Explanations, and the Aims of the Present Study}

The main research question that the present study addressed was: How might the increases in diagram use - resulting from interventions provided - affect the quality of explanations that students produce? The rationale for asking this question was as follows: Previous research indicates that students rely mainly on text or verbal representations to convey information in explanations they produce (e.g., Manalo et al., 2013). However, some recent research findings also indicate that it may be possible to promote more spontaneous use of diagrams in such explanations by providing interventions that effectively convey to students the value of using diagrams, and also cultivate their knowledge and skills in using diagrams (Manalo \& Uesaka, 2016). If such interventions succeed, and students end up including more self-constructed diagrams in the explanations they produce, it would be important then to determine how the quality of the explanations might be affected. For instance, would there be a corresponding reduction in text representations? Would the communication of key points be improved or compromised?

According to Larkin and Simon (1987), diagrams can be superior representations compared to sentential representations because diagrams "group together all information that is used together" and this enables them to more efficiently facilitate search and drawing of inferences from the information that is provided. Mayer (2003), on the other hand, explained that the advantage of including diagrams in communication is that the dual representations (i.e., the diagrammatic and text/verbal representations) enable the use of both visual and verbal channels 
of human information processing, thus making the message that needs to be conveyed much more likely to be understood. However, he also warned about some of the pitfalls of combining visual and verbal representations, noting in particular the importance of coherence and the exclusion of extraneous material from the communication that is created.

The points made by Larkin and Simon (1987) and by Mayer (2003), noted above, suggest that if students are to use more diagrams in explanations they produce - and they do so in an appropriate and effective manner - the diagrams they incorporate would likely represent many of the important points that need to be conveyed to the intended audience of the explanation. Such important points could include not only objects or concrete items and their features, but also processes and mechanisms, actions and sequences, conditions, and so on - depending on what might need to be explained. The diagrams could primarily serve the purpose of supporting what is conveyed in text, or the other way around - text could support what is intended to be conveyed through the diagrams. Either way, if coherence between text and diagrammatic representations is to be achieved - and the inclusion of extraneous material is minimized as Mayer (2003) suggested - then presumably some of the information already represented in diagrams would not be duplicated in text. Hence, there could be a reduction in word count.

If, as Larkin and Simon (1987) suggested, the diagrams group together information that is used together, then they could convey not only physical proximity, but also relationships and processes that exist between the units of information they contain. Thus, there could be a reduction in corresponding sentential or text representations, and this could mean in turn a reduction in the complexity of information conveyed in text - if at least some of those relationships are already represented in diagrams.

A possible outcome then for the explanation that is produced is that it would have more diagrammatic representations and fewer text/sentential representations. However, important points would not be neglected, and many of those points would be represented in diagrams instead of text. To convey various messages in those important points, the types of diagrams used would also evidence increased diversity (i.e., different types would be used to match the requirements of the information to be explained).

Based on these ideas, the following hypotheses were formulated for the present study: (1) That provision of instruction and practice in diagram use would result in increases not only in number but also types of diagrams students use in explanation writing; (2) That inclusion of diagrams would be associated with greater conciseness (lower word count) and simplicity (lower verb count, which is one measure of complexity in writing; cf. Manalo \& Sheppard, 2016); and (3) 
That, despite the conciseness, the inclusion of diagrams would enable the effective communication of key points (i.e., when diagrams are used, fewer words would not correspond to the inclusion of fewer key points).

The present study focused on students for whom English was a foreign language (EFL). This decision was based on the authors' observation that, at various times, most EFL students manifest some difficulties in effectively communicating information in the English language (of course, the frequency and extent of such difficulties depend on their proficiency level and the demands of the task). The reality of 21st Century learning environments, however, is that all students need to attain adequate competence in English communication especially as this language increasingly becomes universally accepted as the global language (e.g., Crystal, 2003; Seidlhofer, 2005). In such environments, students frequently have to explain what they have learned, often in written form and in a limited amount of time (e.g., under test conditions). For EFL students, this can be daunting if they are not so confident in writing in English. Usually, verbal expressions or representations (i.e., written words, phrases, sentences, and paragraphs) are viewed as the only way a student might convey what he or she has learned (cf. Manalo et al., 2013). However, if students are competent in using diagrams or visual representations, there is no compelling reason why they could not incorporate diagrams with text in explanations they produce - as long as their teacher/instructor or examiner allows it. And unless the course is focused on learning the English language, rather than only the subject content, it would seem reasonable to allow the inclusion of diagrams in explanations that students produce. The important point would be to gauge whether the student is able to demonstrate knowledge and/or understanding of the key points in question - and whether they use only words, or words and diagrams in combination, should not matter. Considered from this perspective, diagrams could provide an alternative, more creative way for students to effectively communicate what they know to others. Examining that potential utility is therefore crucial, especially where EFL students are concerned - as the present study set out to do.

\section{METHOD}

\subsection{Participants}

The participants were 19 undergraduate students for whom English was a foreign language (EFL), taking an introductory course in education that was taught entirely in English. The students were aged approximately 19-20 years (females $=10$; Japanese $=12$, other nationalities $=7$ ). Faculty ethics committee approval was obtained prior to the implementation of this study. The students were provided written and verbal explanations at the beginning of the course that some of the 
work they produce would be analyzed for research and course development purposes. They were provided an option of having their work excluded from such analyses and given reassurance that such a decision would in no way affect their assessments and grade in the course. However, all students provided written consent for use of their work.

\subsection{Materials and Procedure}

\subsubsection{Pre- and Post-Instruction Assessments}

The education studies course the students were taking comprised a total of 14 weekly 90 -minute class sessions. At the end of the first and the thirteenth class sessions, the students were administered an assessment task that required reading and note taking from one of two short passages in English. The passages were both just under 600 words in length: one was about the jigsaw classroom, and the other was about theory of mind. These topics were selected because they were similar to the kinds of topics dealt with in the course, but were not included as part of the course. Care was taken in preparing these passages to make them as equivalent as possible. In the first class session, approximately half of the students were randomly given one passage, while the other half received the other passage. The students then received the other passage they had not read in the post-instruction assessment (given during the thirteenth class session).

The procedure used in administering the pre- and post-instruction assessments were the same. The students were allowed 10 minutes to read and take notes from the passage they were given. They received an A4-size sheet of paper on which to take notes, and they were informed that they could use their notes in an explanation task that would follow, but that they would not be able to refer back to the passage they were reading. The students were then given 10 minutes to produce an explanation of the passage they had read, imagining that their audience was another student who knew nothing about that topic.

\subsubsection{Weekly Explanation Homework and Interventions Used}

During the semester, the students had a weekly homework task of writing an explanation of what they had learned from the class session that week. Again, they were asked to write the explanation for an imaginary student naïve about the topic. They were also informed that the explanation should be sufficient on its own (i.e., the reader should understand it without having to be provided additional verbal explanation). The students were provided an A4-size sheet of paper on which to write their explanation, which was collected the following week for instructor comment, and returned the week after that. 
Note that no marks or grades were given for each homework task sheet that the students completed, only written comments about the quality and adequacy of the explanation they produced. The students were required, however, to include those sheets in their portfolio, which they needed to submit at the end of the semester and was worth $40 \%$ of the total course grade. In the grading rubrics for that portfolio, marks were allocated for satisfactory completion and quality features of the homework tasks, but no mention was made of diagrams or of expectations for students to include diagrams. Thus, diagram use in the explanation homework tasks was neither an explicit requirement, nor a feature directly linked to marks or grades.

The interventions used in this study were (1) a hint about the usefulness of diagrams in writing explanations, (2) instruction in the effective use of diagrams for such explanations, and (3) practice in the construction of diagrams to use in explaining various kinds of information. This set of interventions had previously been shown in the Manalo and Uesaka (2016) study to be effective in promoting an increase in students' spontaneous use of diagrams in explanations they produced. However, that study did not examine the effects on quality features of the students' work.

In the first few weeks of the semester (Baseline phase), no intervention was implemented. After that Baseline phase, all the students received a hint about the usefulness of diagrams in writing explanations, given as comment on their homework (thus bringing about the After-Hintphase). The hint was provided as a comment that "including diagrams could make your explanations easier to understand" (the same wording was used for all students). This was written, together with any other comments, on the bottom of students' homework task sheets. The sheets with feedback were returned to students individually during class, and students were encouraged and given a brief amount of time to read over the feedback they had received.

In week 10 of the semester, they were given a 20 -minute workshop on diagram use. The workshop covered reasons for using diagrams (i.e., to help clarify own understanding of the information to be explained, and because research has shown that people learn better from words and pictures than from words alone - e.g., Mayer, 2005), and ways to use diagrams in explanations, including the different purposes they can serve: to illustrate (e.g., layout drawings, sketches), provide overview or structure (e.g., schema/layout diagrams, branching-tree-diagrams), clarify process or causality (e.g., flow-charts), and compare/contrast (e.g., tables, graphs) (AfterInstruction-phase).

Then, in week 11, the students received a 30-minute practice session in constructing appropriate diagrams for different kinds of information to explain (After-Practice-phase). During this session, the instructor quickly reviewed the key points from the instruction about diagram use 
provided in week 10 . Then students were given a photocopy of a weekly explanation homework they had earlier submitted in which they did not use any diagram. The students were provided a new sheet with instructions to consider and draw diagrams they might be able to include to make their explanation easier to understand. During the session, the instructor was available to provide comment and/or feedback, and students could briefly discuss their newly constructed diagrams with other students. In addition to their usual explanation homework, the students were also assigned an extra homework task in week 11, which was to construct one diagram for each of the ways diagrams could be used in explanations using any of the topics/materials that had been covered in the course up to that time. This was assigned to give the students additional practice in constructing diagrams, and it would have likely required about 30 minutes to complete.

\subsection{Analysis}

The numbers and types of diagrams students produced in their homework and Pre- and Postinstruction explanations were counted. For the purposes of this study, a diagram was defined as any representations produced by the students, other than representations in the form of words, sentences, or numbers on their own. For the types, the same categories relating to the functions they serve, referred to during the instructions provided, were used (i.e., four category types: to illustrate, provide an overview, convey process, and compare).

The number of words and verbs (in text and in diagrams) were also counted. As noted in the earlier introductory section, word count was used as a measure of conciseness of the explanations the students produced, and verb count as a measure of simplicity/complexity. The number of verbs used can be considered a good estimate of the complexity of sentence structures, as simple sentences usually contain only one verb and inclusion of more verbs within one sentence usually requires the use of a more complex structure, such as the addition of sub-clauses (Manalo \& Sheppard, 2016). Furthermore, the numbers of specific key points from the two passages that students included in their Pre- and Post-instruction explanations were scored by the second author who was initially blinded to the purpose and details of this study. The two passages used contained the same number of specific key points, and these were determined at the time of constructing the passages to ensure equivalence (see Table 1). Independently, the first author undertook the same scoring, and the interclass correlation coefficient (ICC) between the second and first authors' scores was found to be .982 , which can be considered as excellent agreement (Cicchetti, 1994). 
[INSERT TABLE 1 ABOUT HERE]

The authors deemed it not useful to conduct a similar comparison of key points that the students included in their weekly homework tasks. The reason is that the topics and contents of the lectures that the students had to explain in those homework tasks varied considerably. Thus, unlike the equivalent passages used for their Pre- and Post-instruction explanations, there was considerable variation in the amount and kinds (e.g., theoretical perspectives, details of studies, practical applications, etc.) of information that could be considered as "key points" students should include in those homework explanations - making meaningful comparisons of amount included unrealistic. Such comparisons would have been meaningful only if the students had been given more explicit instruction about the specific aspects (i.e., the kinds of information from the lectures) they needed to include.

\section{RESULTS}

\subsection{Did the number and types of diagrams that students included in their written explanations} increase?

Repeated measures ANOVA (analysis of variance) was used to examine whether there were significant differences on the outcome measures from Pre-instruction to Post-instruction. No significant difference was found between the two types of passages with regard to diagram use in the explanations produced, $F(1,17)=.294, p=.595, \eta_{p}{ }^{2}=.02$. This means that whether the students received the jigsaw classroom passage or the theory of mind passage at Pre-instruction and at Post-instruction did not significantly affect their use of diagrams.

The analysis results also revealed a higher rate (use or not use) of diagram use in explanations at Post-instruction $(M=.63, S D=.50)$ compared to Pre-instruction $(M=.05, S D=.23)$, $F(1,18)=24.75, p<.001, \eta_{p}^{2}=.58$. This means that, compared to Pre-instruction, more students evidenced use of at least one diagram at Post-instruction (see typical examples shown in Fig. 1). The results also revealed that more diagrams (including types) were included in each explanation at Post-instruction $(M=1.84, S D=.16)$ than at Pre-instruction $(M=.16, S D=.69), F(1,18)=20.17$, $p<.001, \eta_{p}{ }^{2}=.53$. This means that that the students used more diagrams in their explanations at Post-instruction (i.e., an average of 1.84 diagrams per explanation, which means just under two diagrams in each explanation) compared to their use at Pre-instruction (i.e., an average of .16 diagram per explanation, which equates to less than one diagram in six explanations). 
[INSERT FIGURE 1 ABOUT HERE]

Additionally, the repeated measures ANOVA conducted for each diagram type indicted significant phase effects for inclusion of diagrams in the homework explanations (i.e., illustrate: $F(3,60)=7.19, p=.0003, \eta_{p}{ }^{2}=.27$; overview: $F(3,60)=10.19, p=.001, \eta_{p}^{2}=.34$; compare: $F(3$, $60)=4.89, p=.004, \eta_{p}^{2}=.20$; process: $\left.F(3,60)=26.96, p<.0001, \eta_{p}{ }^{2}=.57\right)$. This means that the mean inclusion values for each type of diagram (i.e., illustrate-, overview-, process-, and comparetype diagrams) varied across the four phases of Baseline, After-Hint, After-Instruction, and AfterPractice. Šidák post hoc comparisons (Abdi, 2007) indicated that in all diagram types, the mean inclusion value at the After-Practice phase was significantly higher than at the Baseline phase. For both the overview- and process-types of diagrams, the inclusion value at the After-Practice phase was higher compared to all of the other three phases. Furthermore, as Fig. 2 shows, the types of diagrams that the students used in their explanations increased across the phases. At the Baseline phase, for example, none of the students used illustrate-type diagrams, and very few of them used the other three types of diagrams. By the After-Practice phase, however, almost all students were including process-type diagrams, and more than half of them were including the other types of diagrams.

Taken together these results suggest that, following all phases of the intervention (i.e., hint, instruction and practice), students not only included more diagrams in their explanations, but also used more types of diagrams, confirming Hypothesis 1.

\section{[INSERT FIGURE 2 ABOUT HERE]}

\subsection{Was the inclusion of diagrams associated with greater conciseness and simplicity in the explanations that the students produced?}

Correlational analyses revealed that the number of diagrams students included in each explanation negatively correlated with both word count $(r=-.38, p=.056)$ and verb count $(r=-$ $.43, p=.035)$. Both these correlations indicate at least medium size effects, and they confirm Hypothesis 2. In essence, they suggest that the more diagrams the students included in their explanations, the more concise and simple their explanations became (at least in terms of the measures used here). 


\subsection{Were equivalent numbers of key points contained in explanations in which diagrams were} used?

The finding that the more diagrams the students included in their explanations, the more concise and simple their explanations became raised the question of whether, as a consequence of using diagrams, inclusion of key points in the students' explanations might have been negatively affected (i.e., If they were producing more concise and simpler explanations, were they also including fewer key points?). However, analysis of the data showed that this was not the case: the number of key points included in explanations with diagrams $(M=3.83, S D=1.19)$ were in fact slightly higher than for those in explanations without diagrams $(M=3.71, S D=1.11)$, although this difference was not significant, $F(1,17)=1.14, p=.301$. A positive but likewise not significant correlation ( $r=.11$, n.s.) was also found between the number of diagrams (in cases where diagrams were used) and the number of key points included in the students' explanations. These findings indicate that, at the very least, diagram use did not negatively impact inclusion of key points in the explanations. In fact, diagram use could have facilitated - to some extent - the inclusion of more points, although the number of participants in the present study was too low, making the statistical detection of that effect difficult.

\section{DISCUSSION}

This study addressed the mostly neglected question of how diagram inclusion affects the quality features of students' written work. Its findings suggest that diagram inclusion, at least in timed conditions with EFL students, results in more concise and simpler explanations, but without sacrificing the inclusion of key content. As the cultivation of student competencies in use of multiple representations is considered essential in 21st Century educational contexts (e.g., National Research Council, 2012), the findings of the present study can be considered as reassuring. They indicate that enabling student use of multiple representations - in this case, diagrams and text combinations - can easily be facilitated in the context of regular classroom instruction, and the outcomes are promising in terms of communicative effectiveness.

In the following subsections, the possible reasons for the results obtained and the implications of those results for practice will briefly be discussed, before limitations of the study are acknowledged and future directions for research are considered.

\subsection{Concise and Simple $=$ More Efficacious?}


Larkin and Simon's (1987) observations and Mayer's (2003) prescriptions concerning effective diagrams provide basic vehicles for understanding why diagram inclusion in written explanations render those explanations simpler and more concise, without compromising the communication of important content. Diagrams group together information that needs to be used together, and by visually portraying the connections between those items of information, text and sentential representations can be reduced. Verbs can be replaced by arrows and other illustrative mechanisms that convey action and chronological/event sequences. And because they are grouped together, the inferences that need to be drawn from the information represented can become much more salient.

It is of course possible for text and diagrams to end up duplicating each other. This is not necessarily a bad thing if they reinforce or support each other (e.g., what is explained in text can also be illustrated for the sake of clarity) and cohesion in the various strands of information represented is maintained (i.e., the purposes of and relationships between the text and diagrammatic representations are comprehensible to their intended audience). As a general rule, however, extraneous material should be excluded, as they can instead become clutter that detrimentally affects the cohesiveness of the communication content (Mayer, 2003). By eliminating extraneous material, word and verb counts can be reduced - particularly when diagrammatic representations are also employed, because diagrams have the capacity to more efficiently represent information.

Manalo et al. (2013) suggested that one possible explanation why students generally lack spontaneity in using diagrams when explaining what they have learned is educational socialization. Educational environments may convey to students that the use of words and sentences - verbal representations - is the only acceptable means of communicating information in formal and important contexts such as in tests and exams, and assignments and reports. Educational environments may convey those as expectations, not only in instructions that are provided but also in model answers or other works that are shown to students. Yet, if diagrams were included in such communicative efforts, the diagrams could contribute to enhancing their efficacy and accessibility.

Fig. 3 shows two examples of students' written explanations from the weekly homework task administered in the present study. These examples show that with the use of diagrams, more economical use of words can be achieved without the sacrifice of important content. Of course, one could express the view that explanations such as these examples do not look as formally presentable as properly written sentences and paragraphs. But that would be focusing only on 
appearances. Perhaps it would be more important to consider the purposes of the communication, and it can be argued then that these forms of more creative representation of the intended message are far more accessible - let alone more concise and simple - compared to screeds of written text. As noted earlier, they could also be easier to construct for EFL students who may not be as proficient in English, and they may more effectively communicate the points they want to convey compared to the use of words on their own.

\section{[INSERT FIGURE 3 ABOUT HERE]}

\subsection{Implications for Practice}

The results reported in the present study are a consequence of the intervention provided. As reported in the Results section, prior to the interventions, the students' rate of diagram use was very low. In fact, at Baseline, none of them used any illustration-type diagrams at all, and the other types of diagrams were likewise rarely used.

Based on the results of this study, it can be argued that developing student competencies in diagram construction and use can be beneficial to their communicative competence. Thus one vital implication of the present research is that appropriate encouragement, instruction, and practice for the construction and use of diagrams should be provided to students. At the present time, such provisions are rare - in fact almost non-existent - in school or at university. Students are generally expected to develop such competencies by themselves via observing their teachers, and through trial and error. And yet, as demonstrated in the present study, such training can be provided relatively easily. Perhaps a first step to take would be to develop training materials for teacher professional development so that they would be able to develop the knowledge, skills, and confidence for training their own students.

The participants in the present study were also EFL students, and so generally speaking it would not have been as easy for them to write in English (compared to students who are native speakers of that language). When EFL students have to produce written explanations in English, Manalo and Uesaka $(2012,2014)$ have previously reported that they tend to persist in representing information in text and rarely make use of diagrams. This may sound counterintuitive, but based on analysis of data they obtained, Manalo and Uesaka explained that diagram construction requires the use of cognitive resources in working memory, and when students have to use a foreign language, that in itself makes a high demand on cognitive resources in working memory - thus, leaving little or no cognitive resources for the construction of diagrams. However, 
perhaps if the EFL students possessed diagram construction skills, it would not demand as much resources in working memory to produce diagrams for enhancing the quality of their written work. One useful implication of the present study is that, while it is important to cultivate the target language skills in foreign language learners, it is equally important to develop their communicative competencies - and in that, the ability to use multiple representations (including diagrams) is essential. The results of this study clearly suggest that diagram use can enhance the efficacy of their communication. However, foreign language teachers generally do not concern themselves with cultivating competencies in use of multiple representations - at least not the use of diagrams. Thus, some change in this area of education also appears to be necessary.

It should be noted here that lack of spontaneity in use of diagrams in written communication has been detected not just in EFL students but also native English speaking students (Manalo et al., 2013). The importance therefore of cultivating competence and spontaneity in diagram use would apply to students irrespective of their native language and the language that is used in their learning environments.

\subsection{Limitations and Future Directions}

One important limitation of the present study is the small sample size used. Because of the low participant numbers used here, some of the results need to be re-examined in future research, especially those concerning the possibility that diagram use could enable the representation of more key points. It would also be useful in future research to investigate the use of the interventions employed here with other groups of students (e.g., primary, middle, and high school level students), as well as students studying different subject contents.

A practical point that was already signaled earlier is that investment in some teaching and research work on the development of resources for developing teacher competencies in cultivating skills in diagram construction and use in their students would appear valuable to pursue. As teachers teach a range of subject disciplines, this work would need to address both generic and subject-specific principles for and skills in diagram construction and use.

\subsection{Conclusion}

The results of this study provide important confirmation for Larkin and Simon's (1987) observation that "a diagram is (sometimes) worth ten thousand words". Thus, if effective diagrams are constructed and used, it should be possible to cut down on the words and still remain effective in communicating key messages. 
Larkin and Simon, however, also pointed out that to be useful, a diagram needs to be constructed to take advantage of the very features that make them effective (i.e., grouping together of information, providing support for perceptual inferences, etc.). For students to be able to construct such diagrams, instructional interventions are necessary. The present study described one such intervention that worked well. It should therefore be possible to develop and implement such intervention in most classrooms - as long as there is willingness and effort on the part of teachers and school administrators, and educational researchers are committed to providing the support they require. 
List of Funder and Grant Number

This research was supported by a grant-in-aid (XXXXXXXX) received from the Japan Society for the Promotion of Science.

\section{Conflict of Interest}

There is no conflict of interest known to the authors. 


\section{REFERENCES}

Abdi, H. (2007). The Bonferonni and Šidák corrections for multiple comparisons. In N. J. Salkind (Ed.), Encyclopedia of measurement and statistics (pp. 103-107). Thousand Oaks (CA): Sage. Ainsworth, S., Prain, V., Tytler, R. (2011). Drawing to learn in science. Science, 333, 1096-1097. Booth, J. L., \& Koedinger, K. R. (2012). Are diagrams always helpful tools? Developmental and individual differences in the effect of presentation format on student problem solving. British Journal of Educational Psychology, 82, 492-511.

Bui, D. C., \& McDaniel, M. A. (2015). Enhancing learning during lecture note-taking using outlines and illustrative diagrams. Journal of Applied Research in Memory and Cognition, 4, 129-135.

Chen, O., Manalo, E., \& She, Y. (2019). Examining the influence of expertise on the effectiveness of diagramming and summarizing when studying scientific materials. Educational Studies, 45, 5771.

Chu, J., Rittle-Johnson, B., Fyfe, E. R. (2017). Diagrams benefit symbolic problem solving. British Journal of Educational Psychology, 87, 273-287.

Cicchetti, D. V. (1994). Guidelines, criteria, and rules of thumb for evaluating normed and standardized assessment instruments in psychology. Psychological Assessment, 6, 284-290.

Cromley, J. G., Snyder-Hogan, L. E., \& Luciw-Dubas, U. A. (2010). Cognitive activities in complex science text and diagrams. Contemporary Educational Psychology, 35, 59-74.

Crystal, D. (2003). English as a global language (2nd ed.). Cambridge: Cambridge University Press.

De Bock, D., Verschaffel, L., Janssens, D., Van Dooren, W., \& Claes, K. (2003). Do realistic contexts and graphical representations always have a beneficial impact on students' performance? Negative evidence from a study on modeling non-linear geometry problems. Learning and Instruction, 13, 441-463.

Dufour-Janvier, B., Bednarz, N., \& Belanger, M. (1987). Pedagogical considerations concerning the problem of representation. In C. Janvier (Ed.), Problems of representation in the teaching and learning of mathematics (pp. 110-120). Hillsdale, NJ: Erlbaum.

Hegarty, M., \& Kozhevnikov, M. (1999). Types of visual-spatial representations and mathematical problem solving. Journal of Educational Psychology, 91, 684-689.

Hembree, R. (1992). Experiments and relational studies in problem solving: A meta-analysis. Journal of Research in Mathematics Education, 23, 242-273.

Larkin, J. H., \& Simon, H. A. (1987). Why a diagram is (sometimes) worth ten thousand words. Cognitive Science, 11, 65-99. 
Leopold, C., \& Leutner, D. (2012). Science text comprehension: Drawing, main idea selection, and summarizing as learning strategies. Learning and Instruction, 22, 16-26.

Manalo, E., \& Sheppard, C. (2016). How might language affect critical thinking performance? Thinking Skills and Creativity, 21, 41-49.

Manalo, E., \& Uesaka, Y. (2012). Elucidating the mechanism of spontaneous diagram use in explanations: How cognitive processing of text and diagrammatic representations is influenced by individual and task-related factors. Lecture Notes in Artificial Intelligence, 7352, 35-50.

Manalo, E., \& Uesaka, Y. (2014). Students' spontaneous use of diagrams in written communication: Understanding variations according to purpose and cognitive cost entailed. Lecture Notes in Artificial Intelligence, 8578, 78-92.

Manalo, E., \& Uesaka, Y. (2016). Hint, instruction, and practice: The necessary components in promoting spontaneous diagram use in students' written work? Lecture Notes in Artificial Intelligence, 9781, 157-171.

Manalo, E., Uesaka, Y., Kriz, S., Kato, M., \& Fukaya, T. (2013). Science and engineering students' use of diagrams during note taking versus explanation. Educational Studies, 39, 118-123.

Mayer, R. E. (1989). Systematic thinking fostered by illustrations in scientific text. Journal of Educational Psychology, 81, 240-246.

Mayer, R. E. (2003). The promise of multimedia learning: Using the same instructional design methods across different media. Learning and Instruction, 13, 125-139.

Mayer, R. E. (2005). Cognitive theory of multimedia learning. In R. E. Mayer (Ed.), The Cambridge handbook of multimedia learning (pp. 31-48). Cambridge: Cambridge University Press.

National Research Council (2012). Education for life and work: Developing transferable knowledge and skills in the 21st Century. Washington, DC: The National Academies Press.

Padalkar, S., \& Hegarty, M. (2015). Models as feedback: Developing representational competence in chemistry. Journal of Educational Psychology, 107, 451-467.

Seidlhofer, B. (2005). Key concepts in ELT: English as a lingua franca. ELT Journal, 59, 339-341.

Sithole, S. T. M., Chandler, P., Abeysekera, I., \& Paas, F. (2017). Benefits of guided selfmanagement of attention on learning accounting. Journal of Educational Psychology, 109, 220232.

Stull, A. T., \& Hegarty, M. (2016). Model manipulation and learning: Fostering representational competence with virtual and concrete models. Journal of Educational Psychology, 108, 509-527.

Uesaka, Y., \& Manalo, E. (2007). Peer instruction as a way of promoting spontaneous use of diagrams when solving math word problems. In D. S. McNamara, \& J. G. Trafton (Eds.), 
Proceedings of the 29th Annual Cognitive Science Society (pp. 677-682). Austin, TX: Cognitive Science Society.

Uesaka, Y., \& Manalo, E. (2017). How to address students' lack of spontaneity in diagram use: Eliciting educational principles for the promotion of spontaneous learning strategy use in general. In E. Manalo, Y. Uesaka, \& C. A. Chinn (Eds.), Promoting spontaneous use of learning and reasoning strategies: Theory, research, and practice for effective transfer (pp. 62-76). London: Routledge.

Uesaka, Y., Manalo, E., \& Ichikawa, S. (2007). What kinds of perceptions and daily learning behaviors promote students' use of diagrams in mathematics problem solving? Learning and Instruction, 17, 322-335.

Uesaka, Y., Manalo, E., \& Ichikawa, S. (2010). The effects of perception of efficacy and diagram construction skills on students' spontaneous use of diagrams when solving math word problems. Lecture Notes in Artificial Intelligence, 6170, 197-211. 


\section{Figure captions}
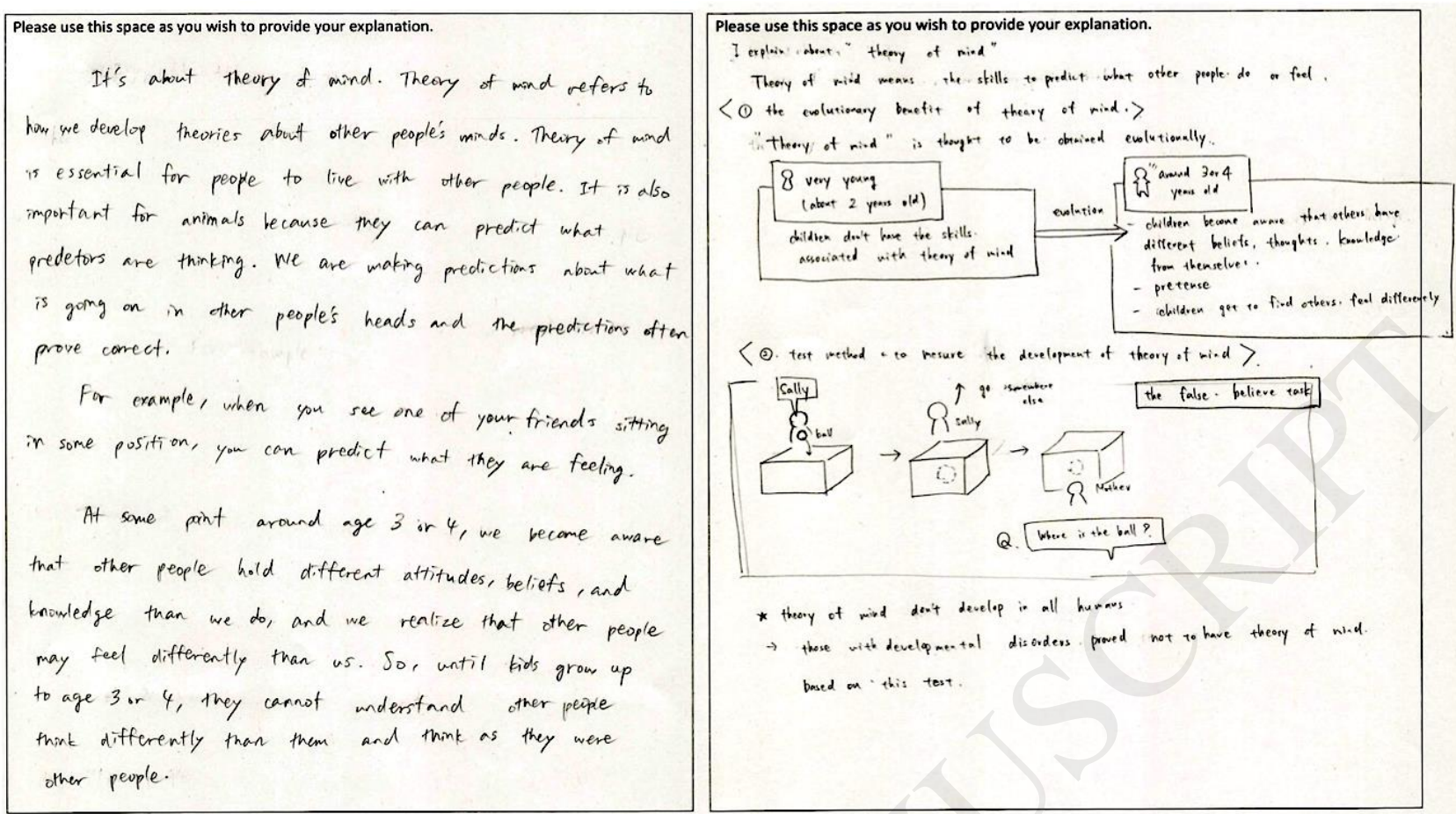

Fig. 1. Examples of typical explanations the students produced: at Pre-Instruction on the left (with usually minimal or no diagrams included) and at Post-Instruction on the right (usually with at least one diagram included). Note that these two explanations were produced by different students. 


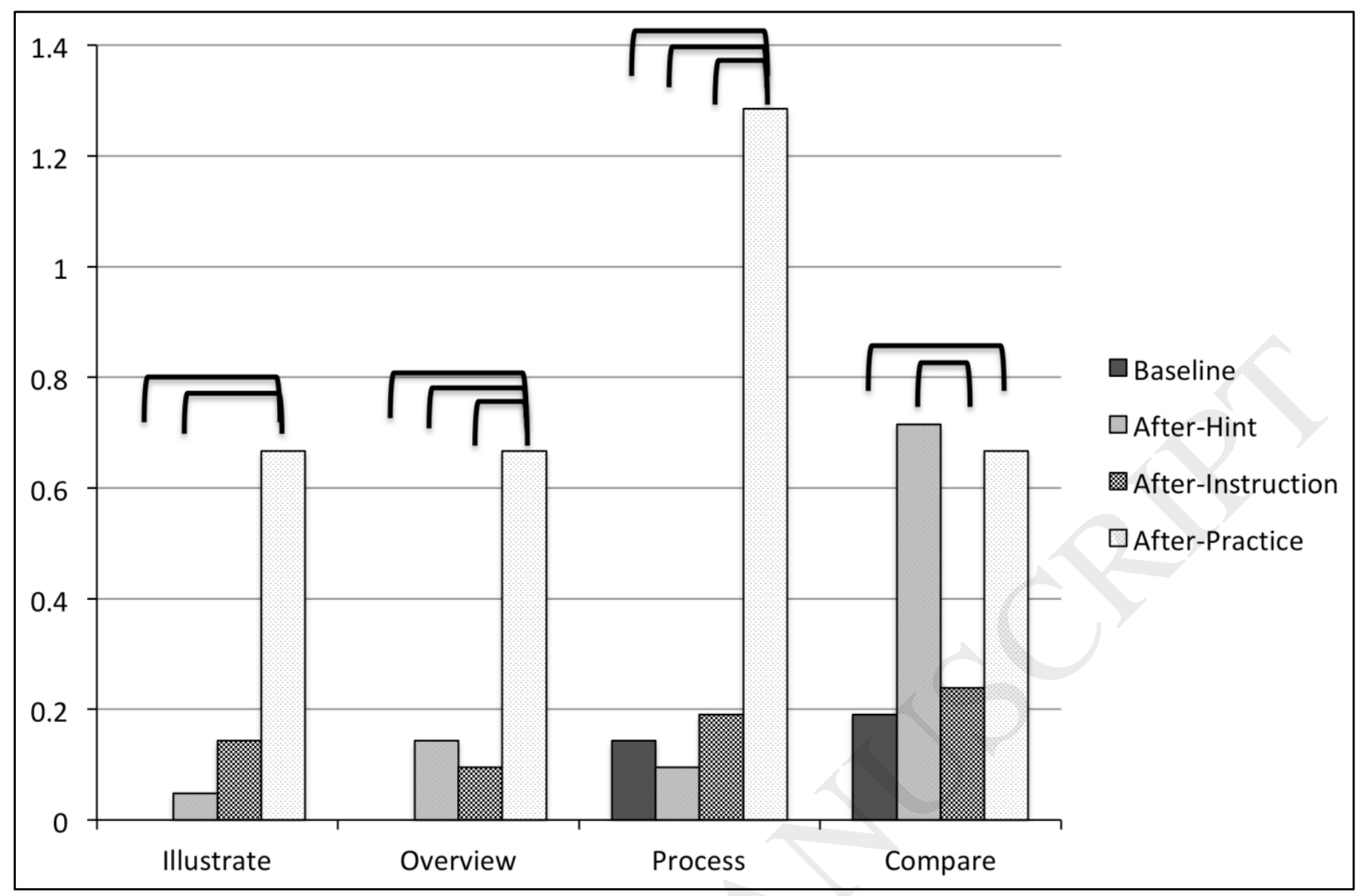

Fig. 2. For each type of diagrammatic representation, mean inclusion values across the Baseline, After-Hint, After-Instruction, and After-Practice phases of the study (bars indicate differences that are significant at $p<.05)$. 


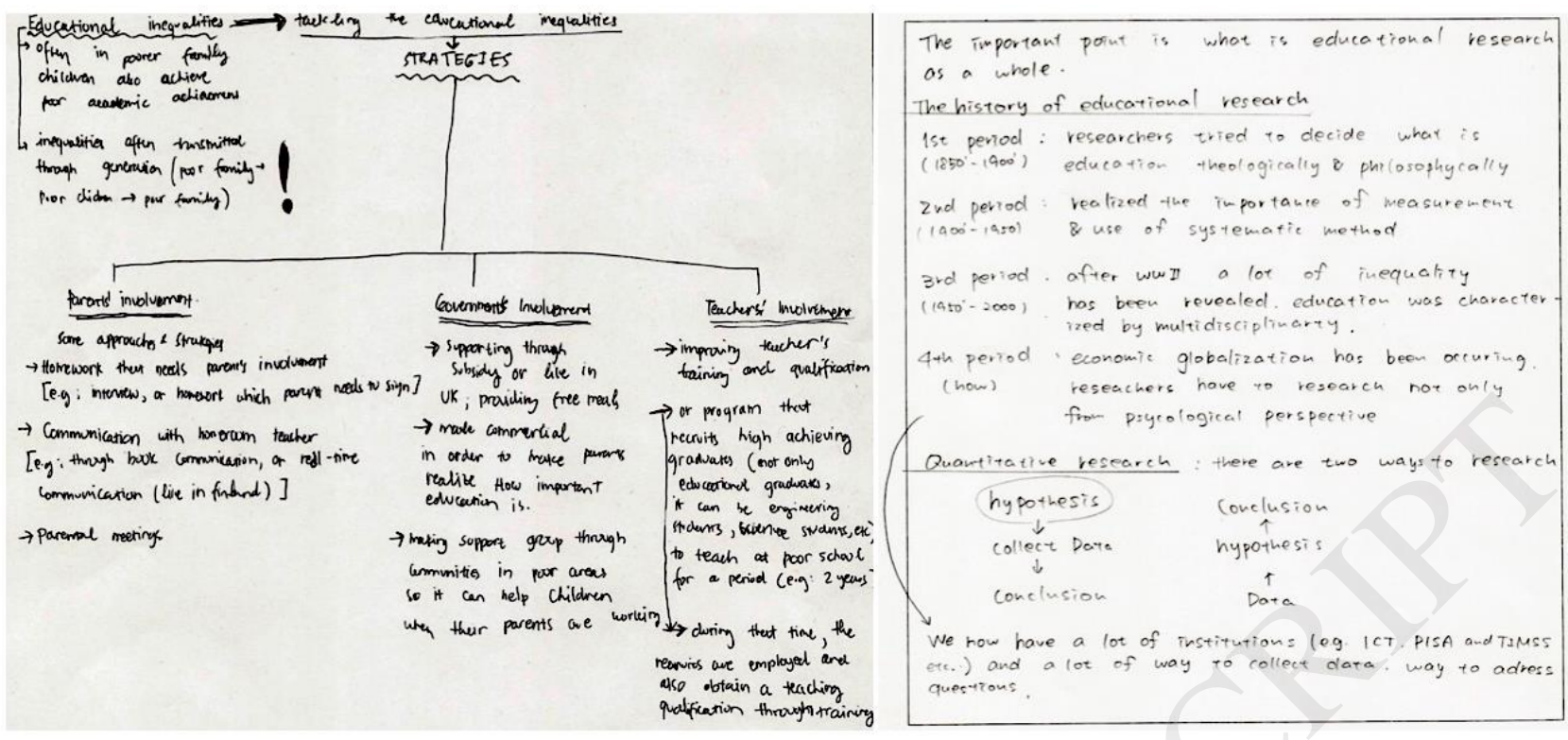

Fig. 3. Two examples of student explanations that incorporate diagrammatic representations and evidence reductions in text/sentential representations. 


\section{Table}

\section{Table 1.}

Key Points from the Two Passages that were Scored for (One Point for the Presence of Each) in the Pre- and Post-Instruction Explanations Produced by the Students

\begin{tabular}{|c|c|}
\hline From the Theory of Mind (ToM) Passage & From the Jigsaw Classroom Passage \\
\hline $\begin{array}{l}\text { 1. Inclusion of definition or explanation of the } \\
\text { meaning of ToM }\end{array}$ & $\begin{array}{l}\text { 1. Inclusion of definition or explanation of the } \\
\text { meaning of the Jigsaw classroom }\end{array}$ \\
\hline $\begin{array}{l}\text { 2. Reference to or explanation of the } \\
\text { evolutionary benefits of having ToM }\end{array}$ & $\begin{array}{l}\text { 2. Reference to the background of the } \\
\text { development of the jigsaw classroom }\end{array}$ \\
\hline $\begin{array}{l}\text { 3. Reference to the development of ToM with } \\
\text { age (difference between very young and } \\
\text { older children) }\end{array}$ & $\begin{array}{l}\text { 3. Reference to or explanation of why the } \\
\text { jigsaw strategy works (shift from } \\
\text { competition to cooperation AND/OR each } \\
\text { contributor being essential in the process) }\end{array}$ \\
\hline $\begin{array}{l}\text { 4. Outline or description of the false-belief } \\
\text { task }\end{array}$ & $\begin{array}{l}\text { 4. Outline or description of how the jigsaw } \\
\text { classroom can be used }\end{array}$ \\
\hline $\begin{array}{l}\text { 5. Reference to individual differences in ToM } \\
\text { development (difference between typical } \\
\text { and atypical/disordered children) }\end{array}$ & $\begin{array}{l}\text { 5. Reference to the crucial mechanism: the } \\
\text { complete picture can only be obtained by } \\
\text { putting all the pieces together }\end{array}$ \\
\hline
\end{tabular}

